International Journal of Biology, Pharmacy and Allied Seiences (IJBPAS)

'A Bridge Betueen Caboratory and QRendo'

Www.iibpas.com

INTERPENETRATING POLYMER NETWORK MATRICES FOR CONTROLLED

DRUG DELIVERY OF PROPRANOLOL HCL USING POLYMERS LOCUST'S

BEAN GUM, GELUCIRE AND SODIUM ALGINATE: A MINI REVIEW

\title{
PAL $M^{1}$, UPADHYAY $S^{2}$ AND UPADHYAY $P^{3}$
}

1: Department of Pharmaceutics, M. Pharm Research Scholar, School of Pharmaceutical

Sciences, IFTM University, Moradabad-244102, Uttar Pradesh, INDIA

2: Department of Pharmacognosy, Faculty of School of Pharmaceutical Sciences, IFTM

University, Moradabad-244102, Uttar Pradesh, INDIA

3: Department of Pharmaceutics, Faculty of School of Pharmaceutical Sciences, IFTM

University, Moradabad-244102, Uttar Pradesh, INDIA

*Corresponding Author: Dr. Munendra Pal: E Mail: munendragangwar2471@gmail.com Received $4^{\text {th }}$ Oct. 2020; Revised $5^{\text {th }}$ Nov. 2020; Accepted $7^{\text {th }}$ Dec. 2020; Available online $1^{\text {st }}$ Sept. 2021

https://doi.org/10.31032/IJBPAS/2021/10.9.5626

\section{ABSTRACT}

Interpenetrating polymer network (IPN) has won quit a few interests in drug delivery machine because of modification throughout its synthesis and improvement state, which advance novel physicochemical and mechanical properties inside the formulation. In this review, an in-depth revision parsing which incorporates its methods of put together. Based on reviewed articles author proposed IPN would be manufactured using Locust bean, Gelucire and sodium alginate form and could be efficiently used in delivery of Propranol $\mathrm{HCl}$, an antihypertensive drug. Here a detailed revision was done which includes its methods of preparations, factors that influence their properties, basic characterization parameters, and use in drug delivery systems along with patented formulations. Now days, The semi IPN and cross linked 3D IPN are having numerous modern therapeutic applications in delivery of bioactive compounds on the form of hydrogel and nanoparticle based drug delivery system. The invention of IPN has reaching and profound long-term implications for the pharmaceutical industry and indeed medicine as a whole.

Keywords: Interpenetrating polymer network, Characterization, Semi-interpenetrating polymer network 


\section{INTRODUCTION}

In the contemporary science of drug discovery, polymer is broadly used and treasured excipients within the unique pharmaceutical formulation. In the modern science of drug discovery, the polymer is widely used and valuable excipients in the different pharmaceutical formulation. It also has a high performance in the parenteral area, controlled drug release, and drug targeting to specific organs. Now in recent years, polymer mixture or blending is used to improve the polymer properties to subside the poor biological properties or progress in mechanical strength of the polymer. Graft copolymerization introduces hydrophobicity and steric bulkiness which significantly protect the matrix from fast dissolution with extended release of drugs $[1,2]$. When single water-loving polymer chain permeates an exceptional community of polymer inside the absence of any chemical bonds between them, then semiIPN was formed. In semi-IPN, a single cross-linked network constructs while in IPN, more than on cross-linked network construct, permeating among them $[3,4]$. Interpenetrating polymer networks (IPNs) are unique "alloys" of crosslinked polymers in which at least one network is synthesized and/or crosslinked in the presence of the other. IPNs are often created for the purpose of conferring key attributes of one of the components while maintaining the critical attributes of another. In some cases, entirely new, and sometimes surprising properties are exhibited by the IPN that are not observed in either of the two single networks along [5]. In the pharmaceutical industry there is a significance demand for new materials with the high safety, effectiveness and innovative formulation consequently much research effort has been directed towards the development of new function drug carriers using natural polymers which have high biocompatibility and biodegradability [6]. The most widely use biopolymer are sodium alginate, locust bean gum and gelucire [7, 8]. The polymer can be exploited in various way according to their different function group, wide range of molecular weight, and chemical composition [9]. Tamarind seed polysaccharide is an emerging excipient tamarind gum $\mathrm{TG}$ and modified $\mathrm{TG}$ are found to be appropriate for the designing of oral, nasal, ophthalmic, colonic and topical drug delivery systems. Moreover, they are used in the preparation of hydrogel-based drug delivery systems and novel drug delivery systems such as nanoparticles [10]. The invention of IPN has reaching and profound long-term implications for the pharmaceutical industry and indeed medicine as a whole. Because of their propensity to combine with other polymers 
to form cross linked three-dimensional interpenetrating polymer network (IPN) hydrogels that tend to swell in water or biological fluids. Such IPN hydrogel systems have been considered as a potential candidate to deliver bioactive molecules, particularly in controlled release applications to deliver the drugs at, constant rate over an extended period of time. Therefore, formation of IPN hydrogel appears to be a better approach [11].
An elastic semi IPN from guar gum (GG), xanthan gum (XG) and poly(acrylic acid) (PAA) was developed and used as a bioadsorbent for soluble $\mathrm{Pb}$ (II) and $\mathrm{Hg}$ (II) from water. The IPNs were developed using a photo-initiated crosslinking cum polymerization approach (benzophenone was used as an initiator) with a variable composition of the biopolymers (GG:XG fixed at $20: 80$ by mass) to PAA by mass (Biopolymers: PAA as 90:10, 80:20, 70:30 and 50:50, respectively) [3].

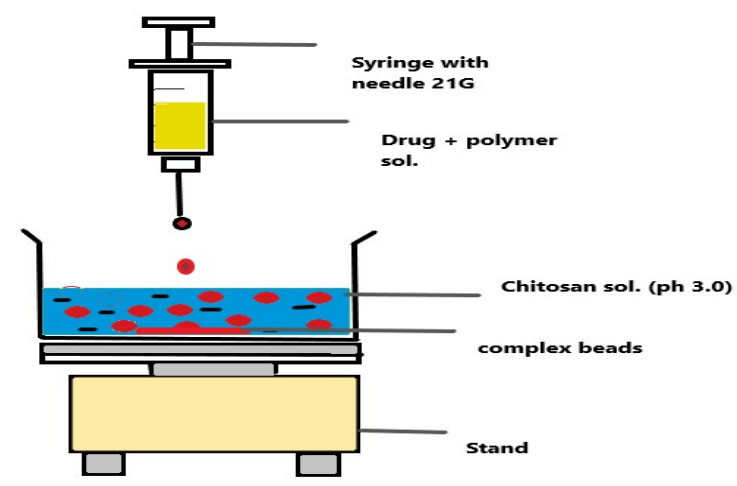

Figure 1: Photographs of formed microspheres

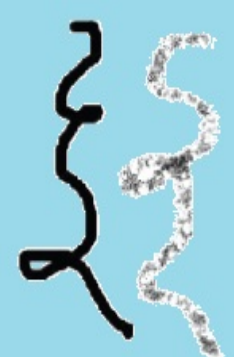

(a)

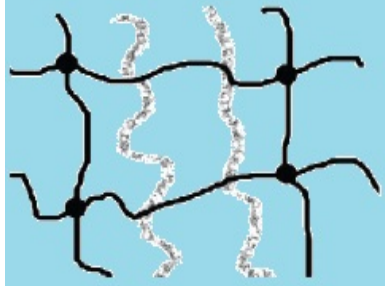

(d)

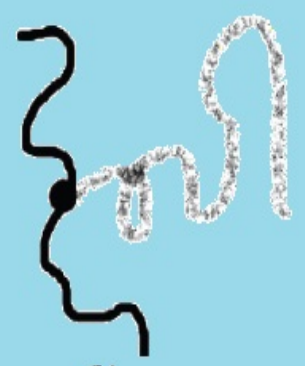

(b)

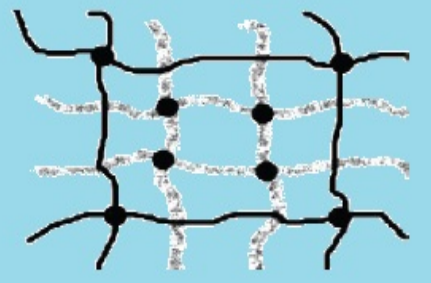

(e)

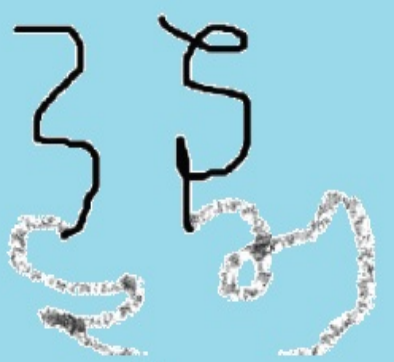

(c)

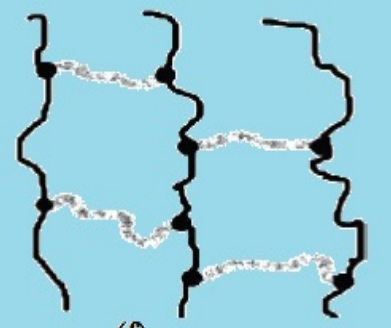

(f)

Figure 2: (a) A polymer blend; (b) a graft copolymer; (c) a block copolymer; (d) semi-IPN; (e) full IPN; F- crosslinked copolymer 


\section{Advantages of IPN}

There are the following inherent advantages due to which IPN system gained huge popularity in the modern era of polymers. They are as follows-

1. IPN system allow in increasing the mechanical strength, phase stability and biological acceptability for every last product.

2. IPN is also like wise beneficial in producing the synergistic effect from the component polymer.

3. Due to the infinite zero-viscosity of the gel, segment separation among the component polymers is not possible.

4. Due to permanent interlocking of the network segment, thermodynamic incompatibility can be made to overcome as the reacting ingredients are blended thoroughly at the time of synthesis.

5. IPN additional potent to increase the controlled release system for handing over the drug.

6. When the blends are subjected to stress, they hold the stages separate [12].

\section{Disadvantages of IPN}

The main disadvantage of IPN is that, on occasion the polymers interpenetrate to such a quantity and the drug launched from the matrix will become difficult. The problem with the non-covalent system is that it can also be a problem with the covalent system due to the lack of an effective interface [13].

\section{Features of IPN}

There are the subsequent ideal traits of IPN which can be as follows-

In perfect IPN creep and flow is suppressed. IPN can swell however does no longer dissolve in solvent. IPN has excessive tensile strength. Most ideal IPNs are heterogeneous structures which include one rubbery phase and one glassy segment to supply a synergistic impact yielding. When the blends are subjected to stress, they keep the phases separated collectively. IPN specially forms insoluble network. IPN systems differ mainly because of the wide variety and forms of cross-hyperlinks. They show adhesive property. Hence, IPN based totally structure have won good ability to broaden the controlled release delivery of drugs [14].

\section{Classification of IPN}

\section{Based on chemical bonding}

Covalent semi IPN- A covalent semi IPN carries two separate polymer systems which can be cross linked to form single polymer network.

Non-covalent semi IPN- A non-covalent semi IPN is one in which simplest one of the polymer systems is cross connected.

\section{Covalent semi IPN}

\section{Novel (IPN)}

Semi (IPN) 


\section{Sequential (IPN)}

Simultaneous interpenetrating polymer network (SIPN)

Latex (IPN)

Gradient (IPN)

Thermoplastic (IPN)

\section{IPN based Drug Delivery System}

IPN based drug delivery structure are used to supply the drug at a selected charge for preferred time fare with low fluctuation. Now a days, there are many approaches which can be being used for improving the transport of healing substance like films, hydrogels, tablets, capsules, microspheres, sheets, sponges, matrix, transdermal patches, nanoparticles etc. Some of the important IPN based totally drug shipping structure are discussed here [15]. In many animal models, after implantation of transfected cells, a lengthy-term period expression of the overseas gene has not been completed [16]. Environmentally sensitive hydrogels can be created from hydrophilic, stimuli-responsive polymer networks that can alternate the volume in response to an outside signal such as a trade in temperature or chemical environment. These materials are appealing and candidate for various biomedical applications and artificial muscles [17].

\section{Ionotropic gelation method}

This method is based on the interaction of an ionic polymer with opposite charge polymer. Sodium alginate and the polymer were dispersed and blended thoroughly in distilled water and stirred for entire solubility [18]. Then, the answer becomes poured dropwise with the assist of 23 gauze syringe needle to some other aqueous media of another ionic polymer $(\mathrm{Al}+3, \mathrm{Ca}+2$, etc. $)$ with persisted stirring [19].

\section{Emulsification cross-linking}

This approach is primarily based on segment separation. This method is used broadly to form a cross-connected polymer community. Usually, the cross-linked is prepared by means of water-in-oil (w/o) emulsion [2]. In w/o emulsification aqueous polymeric solution changed into prepared by adding the water-soluble polymer shape homogeneous answer by means of stirring. After that, this aqueous phase became brought to the oil section. Recently, waterin-water $(\mathrm{w} / \mathrm{w})$ emulsion has been developed to shape IPN. The toxicity impact of $\mathrm{w} / \mathrm{w}$ emulsion is much less evaluating to w/o emulsion as there is no need of an organic solvent as w/w emulsification method is completely depending on the aqueous environment [9, 20].

\section{Wet granulation method}

Wet granulation is a technique of mixing of dry powder with granulating fluid which may be removed by way of drying. The liquid solution that is used for granulation may be either aqueous based totally or solvent primarily based. The required 
amount of polymer is blended manually for 15 min. Then, the required amount of mixing agent is delivered to put together cohesive mass and the moist mass passive through \# 22/24 mesh screen. The resulting is dried at $40^{\circ}-60^{\circ} \mathrm{C}$ for $12 \mathrm{~h}$. After finishing touch of the drying level, the dry granules had been passed through \#22 mesh screen. Then, magnesium stearate mixed with the granules and compressed right into a tablet $[\mathbf{2 1}, \mathbf{2 2}]$.

\section{Pharmaceutical factors influencing}

\section{Mechanical strength}

In the field of pharmaceutical utility, the mechanical belonging of IPN is a crucial factor. During the life span of application, the integrity of the drug transport gadget desire to be maintained unless that is designed as a biodegradable polymer. A drug delivery system is designed to shield sensitive healing agent until its miles launched out of the system and consequently the machine desire to maintain its integrity [23]. To achieve the desired mechanical assets of the IPN, the degree of cross-linking is to be modified accordingly. A boom inside the degree of cross-linking of the device results in a sturdy polymer network, but this may boom the brittleness within the structure of the system. Hence, an optimum degree should be achieved and maintained to get a comparatively strong IPN-primarily based drug shipping system and also now not permitting to be brittle. Another technique to achieve the preferred mechanical properties of IPN is copolymerization [24].

\section{Large scale production}

Large scale production is a challengeable project for IPNs drug transport. IPNs are usually investigated for laboratory scale for improved performance instead than big scale. The problem in big scale is to keep the awareness the concentration and composition of polymers. Hence, it is an ongoing technique to scale up IPNs production process. There are pretty a lot of factors such as improving the selectivity and non-compromising biocompatibility, stability, use of right engineering configurations, optimizing polymer modification techniques and using costeffective substance and methods which can affect the scale-up method [25].

\section{Sterilization}

In the past decade, intensive studies on the field of IPNs for drug transport package has been done. The most widely employed technique is steam sterilization by autoclaving at $121^{\circ} \mathrm{C}$., but it has challenge for its use in maximum of the polymeric materials, as it has a possibility of inducing melting and/or hydrolysis of the polymer matrixe [26]. For its powerful treatment at ambient temperature, chemical sterilization with ethylene oxide gas is used for hydrolytically unstable polymers. The biocompatibility of the biopolymer is 
retained as chemical additives are not used in the radiation cross-linking $[\mathbf{2 7}, \mathbf{2 8}]$.

\section{Characterization of IPN}

Different characterization methods were cited in pieces of literature for evaluation of IPN microbeads as well as microsphere formulations $[29,30]$. Some of them are :

\section{Particle length evaluation}

By the help of a virtual microscope or optical microscope, the debris size can be determined. In an optical microscope, the eyepiece micrometre is calibrated using the degree micrometre. This process is tedious and in particular used throughout laboratory scale up [31].

\section{Fourier-transform infrared analysis}

It is an analytical technique, which is used to identify the functional group in structure and intermolecular interaction of organic, polymeric and in some cases inorganic materials. The samples were crushing with potassium bromide [32]. Then under hydraulic pressure of $600 \mathrm{~kg}$, the samples were converted into pellets and they were scanned in the range of 500 and $4000 \mathrm{~cm}^{-1}$ [8].

\section{Drug entrapment performance}

The amount of drug absorbed into IPN particles is estimated by drug entrapment efficiency. The required amount of IPN particles was pasted in mortar and pestle and dissolved in $50 \mathrm{ml}$ solution of phosphate buffer $(\mathrm{pH} 6.8)$. At $50^{\circ} \mathrm{C}$, the solution was heated for producing desired drug extraction. The drug extracted is calculated by suitable analytical spectroscopy technique $[\mathbf{5}, \mathbf{3 3}]$.

\section{Percentage of yield}

It is calculated by the ratio of the total amount of the organized microspheres and the preliminary weight of polymer and drug which is taken as the theoretical value Propranolol is a beta-blocker. Beta-blockers have an effect on the coronary heart and circulation (blood drift through arteries and veins) $[32,34]$.

\section{Propranolol $\mathrm{HCl}$, an antihypertensive drug:}

Propranolol is used to treat tremors, angina (chest

pain), hypertension (high blood pressure), heart rhythm disorders, and other heart or circulatory conditions. It is also used to treat or prevent heart attack, and to reduce the severity and frequency of migraine headaches ${ }^{[35]}$. Hemangeol (propranolol oral liquid 4.28 milligrams) is given to toddlers who are at least 5 antique to treat a genetic condition called infantile haemangiomas. Haemangiomas are caused by blood vessels grouping together in an abnormal way. These blood vessels form benign (noncancerous) growths that can develop into ulcers or red marks on the skin [36]. The pure drug propranolol $\mathrm{HCl}$ showed rapid and complete dissolution within $60 \mathrm{~min}$, while drug release from resinate was extended for $2.5 \mathrm{~h}$ and that from IPN tablets 
was still slower and drug release prolonged over $18 \mathrm{~h}$. The crosslinking time of granules affected the release of drug from IPN matrix [21].

\section{Polymers discussed in IPN formuations} are :

\section{Locust bean gum powder}

It is extract from the seeds of the carob tree, that is local to the Mediterranean region and nearly $75 \%$ have been produced by way of Portugal, Italy, Spain and Morocco in 2016. The seeds contained in the long pods that grow on the tree are used to make this gum. First, the pods are kibbled to spilt the seed from the pulp. Then, the seeds have their skins removed by an acid treatment; the deskinned seed is then cut up and gently milled. This causes the brittle germ to interrupt up at a same time as no longer affecting the extra robust endosperm [7]. The two are separated by sieving's. The separated endosperm can then be milled through a curler operation to produce the final locust bean gum powder [37].

\section{Gelucire 39/01}

It is a defensive provider for API sensitive to oxidation, humidity or light. It is a lipid for use in modified release dosage bureaucracy (lipid matrix in capsules, floating granules) $[4,38]$. It is used as a lipid binder in soften strategies where the physicochemical homes and plasticity of the lipid agglomerate provides high resistance to fracture. It is beneficial for flash soften and chewable tablets. It is used as consistency agent (thickener) for topical formulations. It has HLB value 1 and melting point of $39^{\circ} \mathrm{C}$. Hydrogels were prepared by freeze-drying an aqueous dispersion of the polymer in the presence or absence of either a model macromolecule fluorescein isothiocyanatedextran, and/or amphiphilic derivatives, gelucire $50 / 13$ or vitamin $\mathrm{E}$, d$\alpha$-tocopherol polyethylene glycol succinate [39]. It can be formulated by melt granulation or melt extrusion techniques for capsule filling, tabletting, sachets etc [40, 41].

\section{Sodium Alginate}

Sodium Alginate is an herbal polysaccharide product extracted from brown seaweed that grows in cold water regions. It is soluble in cold and warm water with robust agitation and many thicken and bind. In presence of calcium, sodium alginate forms a gel without the need of heat. In modernist cuisine, sodium alginate is mostly used with calcium salts to produce small caviar-like and large spheres with liquid inside that burst in the mouth. Sodium Alginate is likewise used within the meals industry to increase viscosity and as an emulsifier. It is also utilized in indigestion pills and it has no discernible flavour [19, 21]. Combination of biopolymers sodium alginate and locust bean gum has been used to prepare an 
interpenetrating polymeric network of an anticancer drug Capecitabine by ionotropic gelation method [42].

\section{COCLUSION}

In multi-component polymer literature, the IPN capability is one of the oldest in addition to the most modern and rapidly evolving field. In polymer know-how technology, IPN and semi-IPN technologies have been studied for more than 60 years. However, IPN has not been fully used as biomaterial in tissue engineering and drug delivery, used together in various fields of science such as fuel cells, superstar cages and packing dishes, and is used to improve the industrial use of new substances and consumer products. With the IPN concept, we can produce a very small domain length of a dual-phase substance. IPN has many benefits along with swelling ability, mechanical strength, specificity, oxygen permeability, nutrients, and strength in the body. This may be the result of the presence of cross compounds in each polymer that reduce the creep and flow and streams and flows and allow a relatively large amount of material with a larger module space.

\section{Consent for publication}

Not applicable.

\section{Conflects of intrest}

The authors confirm that this article content has no conflict of interest.

\section{Acknowledgemnt}

Authors are thankful to Prof M.P.Pandey, Hon'ble Vice Chancellor, IFTM University for providing the research facility at Central Instrument Facility and School of Pharmaceutical Sciences of IFTM University, Moradabad-244102, U.P, India

\section{REFERENCE}

[1] Giri TK, Thakur D, Alexander A, Ajazuddin, Badwaik H, Tripathy M, et al. Biodegradable IPN hydrogel beads of pectin and grafted alginate for controlled delivery of diclofenac sodium. J Mater Sci Mater Med 2013; 24(5): 1179-90.

[2] Siegfried DL, Thomas DA, Sperling LH. Thermoplastic interpenetrating polymer networks of a triblock copolymer elastomer and an ionomeric plastic. I. Rheology and morphology. J Appl Polym Sci 1981; 26(1): 177-92.

[3] Pal A, Das T, Sengupta S, Sardar S, Mondal S, Bandyopadhyay A. An elastic semi IPN polymer hybrid for enhanced adsorption of heavy metals. Carbohydr Polym 2020; 236: 116055

[4] Siddhanta SK, Gangopadhyay R. Conducting polymer gel: formation of a novel semi-IPN from polyaniline and crosslinked poly(2acrylamido-2-methyl 
propanesulphonicacid). Polymer 2005; 46(9): 2993-3000.

[5] Myung D, Waters D, Wiseman M, Duhamel P-E, Noolandi J, Ta CN, et al. Progress in the development of interpenetrating polymer network hydrogels. Polym Adv Technol 2008; 19(6): 647-57.

[6] Sperling LH. Interpenetrating Polymer Networks and Related Materials [Internet]. Boston, MA: Springer US; 1981 [cited 2020 Aug 6]. Available from: http://link.springer.com/10.1007/97 8-1-4684-3830-7

[7] Upadhyay M, Adena SKR, Vardhan H, Yadav SK, Mishra B. Locust bean gum and sodium alginate based interpenetrating polymeric network microbeads encapsulating Capecitabine: Improved pharmacokinetics, cytotoxicity \&in vivo antitumor activity. Mater Sci Eng C 2019;104:109958.

[8] Upadhyay P, Pandit JK, Wahi AK. Studies on biological macromolecules lipid-Gelucire based gastroretentive multiparticulate. Int J Biol Macromol 2014; 67: 463-477.

[9] Song P, Wu Y, Zhang X, Yan Z, Wang $\mathrm{M}, \mathrm{Xu}$ F. Preparation of Covalently Crosslinked Sodium Alginate/Hydroxypropyl

Methylcellulose $\quad \mathrm{pH}-$ Sensitive
Microspheres for Controlled Drug Release. BioResources 2018; 13(4): 8614-28.

[10] Mali KK, Dhawale SC, Dias RJ, Ghorpade VS. Delivery of drugs using tamarind gum and modified tamarind gum: A review. Bull Fac Pharm Cairo Univ 2019; 57(1): 124.

[11] Sperling LH. Interpenetrating Polymer Networks and Related Materials. Springer Science \& Business Media; 2012.

[12] Kausar A. Interpenetrating polymer network and nanocomposite IPN of polyurethane/epoxy: a review on fundamentals and advancements. Polym-Plast Technol Mater 2019; 58(7): 691-706.

[13] Mathew AjiP. Interpenetrating Polymer Networks: Processing, Properties and Applications [Internet]. In: Visakh PM, Thomas S, Chandra AK, Mathew AjiP, editors. Advances in Elastomers I. Berlin, Heidelberg: Springer Berlin Heidelberg; 2013 [cited 2020 Aug 6]. page 283-301. Available:http://link.springer.com/ 10.1007/978-3-642-20925-3_10

[14] Lipatov YS, Alekseeva TT. PhaseSeparated Interpenetrating Polymer Networks [Internet]. In: 
Phase-Separated Interpenetrating

Polymer Networks. Berlin,

Heidelberg: Springer Berlin

Heidelberg; 2007 [cited 2020 Aug

6]. page 1-227. Available from: http://link.springer.com/10.1007/1

2_2007_116

[15] Sperling LH. Interpenetrating Polymer Networks: An Overview [Internet]. In: Klempner D, Sperling LH, Utracki LA, editors. Interpenetrating Polymer Networks. Washington, DC: American Chemical Society; 1994 [cited 2020 Aug 6]. page 3-38. Available from: https://pubs.acs.org/doi/abs/10.102 1/ba-1994-0239.ch001

[16] Lin Q, Zheng Y, Ren L, Wu J, Wang $\mathrm{H}$, An J, et al. Preparation and characteristic of a sodium alginate/carboxymethylated bacterial cellulose composite with a crosslinking semiinterpenetrating network. J Appl Polym Sci 2014; 131(3): 39848.

[17] Kim SC, Klempner D, Frisch KS, Radigan W, Frisch HL. Polyurethane Interpenetrating Polymer Networks. I. Synthesis and Morphology of PolyurethanePoly(methyl methacrylate) Interpenetrating Polymer
Networks. Macromolecules 1976; 9(2): 258-63.

[18] Ha SM, Yuan W, Pei Q, Pelrine R, Stanford S. Interpenetrating Polymer Networks for HighPerformance Electroelastomer Artificial Muscles. Adv Mater 2006; 18(7): 887-91.

[19] Kulkarni AR, Soppimath KS, Aminabhavi TM, Dave AM. Polymeric sodium alginate interpenetrating network beads for the controlled release of chlorpyrifos. J Appl Polym Sci 2002; 85(5): 911-8.

[20] Solak EK. Preparation and Characterization of IPN Microspheres for Controlled Delivery of Naproxen. J Biomater Nanobiotechnology 2011; 02(04): 445-53.

[21] Kulkarni RV, Baraskar VV, Mallikarjun Setty C, Sa B. Interpenetrating polymer network matrices of sodium alginate and carrageenan for controlled drug delivery application. Fibers Polym 2011; 12(3): 352-8.

[22] Wu Q-X, Lin D-Q, Yao S-J. Design of Chitosan and Its Water Soluble Derivatives-Based Drug Carriers with Polyelectrolyte Complexes. Mar Drugs 2014; 12(12): 6236-53. 
[23] Matricardi P, Di Meo C, Coviello T, Hennink WE, Alhaique F. Interpenetrating Polymer Networks polysaccharide hydrogels for drug delivery and tissue engineering. Adv Drug Deliv Rev 2013; 65(9): 1172-87.

[24] Lohani A, Singh G, Bhattacharya SS, Verma A. Interpenetrating Polymer Networks as Innovative Drug Delivery Systems. J Drug Deliv2014; 2014: 1-11.

[25] Gupta NV, Shivakumar HG. Interpenetrating Network Superporous Hydrogels For Gastroretentive ApplicationPreparation, Swelling And Mechanical Properties. Turk J Pharm Sci 2012; 9(2): 127-38.

[26] Elsharawy AM, Shukr MH, Elshafeey AH. Optimization and in vivo evaluation of duloxetine hydrochloride buccoadhesive lyophilized tablets. J Drug Deliv Sci Technol 2019; 52: 282-91.

[27] Bhardwaj V, Harit G, Kumar S. Interpenetrating polymer network (IPN): novel approach in drug delivery. Int J Drug Dev Res 2012; 4(3): 41-54.

[28] Jain N, Kumar Sharma P, Banik A, Gupta A, Bhardwaj V. Pharmaceutical and biomedical applications of interpenetrating polymer network. Curr Drug Ther 2011; 6(4): 263-270.

[29] Niu Y, Xia Q, Li N, Wang Z, (Lucy) Yu L. Gelling and bile acid binding properties of gelatinalginate gels with interpenetrating polymer networks by double cross-linking. Food Chem 2019; 270: 223-8.

[30] Sun X-F, Zeng Q, Wang H, Hao Y. Preparation and swelling behavior of $\mathrm{pH} /$ temperature responsive semi-IPN hydrogel based on carboxymethyl xylan and poly(N-isopropyl acrylamide). Cellulose 2019; 26(3): 1909-22.

[31] Shah S, Ranjha NM, Javaid Z. Development and evaluation of $\mathrm{pH}$-dependent interpenetrating network of acrylic acid/polyvinyl alcohol. Iran Polym J 2013; 22(11): 811-20.

[32] Kulkarni RV, Baraskar VV, Alange VV, Naikawadi AA, Sa B. Controlled release of an antihypertensive drug through interpenetrating polymer network hydrogel tablets of tamarind seed polysaccharide and sodium alginate. J Macromol Sci Part B 2013; 52(11): 1636-1650.

[33] Qiao J, Okada T. Highly Durable, Proton-Conducting Semi-interpenetrating Polymer Networks from 
PVA/PAMPS Composites by

Incorporating Plasticizer Variants.

Electrochem Solid-State Lett 2006; 9(8): A379.

[34] Murthy TGK, Kishore VS. Effect of casting solvent and polymer on permeability of propranolol hydrochloride through membrane controlled transdermal drug delivery system. Indian J Pharm Sci 2007; 69(5): 646.

[35] Siahi-Shadbad MR, Asare-Addo K, Azizian K, Hassanzadeh D, Nokhodchi A. Release behaviour of propranolol $\mathrm{HCl}$ from hydrophilic matrix tablets containing psyllium powder in combination with hydrophilic polymers. AapsPharmscitech 2011; 12(4): 1176-1182.

[36] Javadzadeh Y, Musaalrezaei L, Nokhodchi A. Liquisolid technique as a new approach to sustain propranolol hydrochloride release from tablet matrices. Int $\mathrm{J}$ Pharm 2008; 362(1-2): 102-8.

[37] Kaity S, Ghosh A. Carboxymethylation of Locust Bean Gum: Application in Interpenetrating Polymer Network Microspheres for Controlled Drug Delivery. Ind Eng Chem Res 2013; 52(30): 10033-45.
[38] Upadhyay P, Pandit JK. Dissolution, HSPM, PXRD, DSC studies on gastro retentive multiparticulates of metformin hydrochloride for the treatment of diabetes using gelucire. Lat Am J Pharm 2011; 30.

[39] Martin L, Wilson CG, Koosha F, Tetley L, Gray AI, Senel S, et al. The release of model macromolecules may be controlled by the hydrophobicity of palmitoyl glycol chitosan hydrogels. J Controlled Release 2002; 80(1): 87-100.

[40] Chauhan B, Shimpi S, Mahadik KR, Paradkar A. Preparation and evaluation of floating risedronate sodium Gelucire ${ }^{\circledR}$ 39/01 matrices. Acta Pharm 2004;54(3):205-14.

[41] Juárez-Soberanez D, VillafuerteRobles L. Gelucire 39/01 as excipient for gastroretentive metronidazole sustained delivery. Int J Pharm Pharm Sci 2011; 86-91.

[42] Kulkarni AR, Soppimath KS, Aminabhavi TM, Dave AM, Mehta MH. Glutaraldehyde crosslinked sodium alginate beads containing liquid pesticide for soil application. $\mathrm{J}$ Controlled Release 2000; 63(1): 97105. 